\title{
Thiols' extraction from "Jet-Fuel” assisted by ionic liquids in hollow fibre membrane contactors
}

Ana R. Ferreira ${ }^{\S}$, Luísa A. Neves ${ }^{\S}$, Jorge C. Ribeiro ${ }^{\ddagger}$, Fernando M. Lopes ${ }^{\ddagger}$, João A.P. Coutinho $^{¥}$, Isabel M. Coelhoso ${ }^{\S}$ and João G. Crespo*§

$\S$ CQFB/REQUIMTE, Departamento de Química, FCT, Universidade Nova de Lisboa, 2829-516 Caparica, Portugal

¥Departamento de Química, CICECO, Universidade de Aveiro, 3810-193 Aveiro, Portugal

‡ Galp Energia, Refinaria de Matosinhos, 4452-852 Leça da Palmeira, Matosinhos, Portugal

${ }^{*}$ Corresponding author

Tel: +351-212 948 300; Fax: +351-212 948 550; $\quad$ E-mail address: jgc@fct.unl.pt

\begin{abstract}
This work proposes an alternative technique for the selective extraction of thiols from a "jet-fuel" model stream, using the 1-ethyl-3-methylimidazolium triflate $\left(\left[\mathrm{C}_{2} \mathrm{mim}\right]\left[\mathrm{CF}_{3} \mathrm{SO}_{3}\right]\right)$ ionic liquid as extractant, in a hollow fibre membrane contactor. Due to the low distribution ratio of the thiol towards the ionic liquid, observed in single extraction, a regeneration step (stripping with vacuum or a sweep gas) was added to the extraction process, in order to maximize the concentration gradient overcoming thermodynamic constraints. The stripping with a sweep gas allowed for a complete regeneration of the ionic liquid producing a jet-fuel with sulphur content lower than 2 $\mathrm{ppm}$. Since the controlling step of the process is the extraction of thiol from the feed phase to the ionic liquid phase, the increase of the ionic liquid velocity and operating temperature may further enhance the process performance. The results obtained along with the ultra-low sulphur jet-fuel model produced, prove the high potential of this integrated process as an alternative method for replacing the current expensive desulphurization process.
\end{abstract}


Keywords: desulphurization; thiols removal; jet-fuel; ionic liquid extraction; hollow fibre membrane contactor.

\section{Introduction}

The removal of sulphur from fuel streams in the refining industry is currently and primarily carried out by hydrodesulphurization processes, which consist mainly in a catalytic hydrogenation of organic sulphur compounds producing hydrogen sulphide $\left(\mathrm{H}_{2} \mathrm{~S}\right)$, at very high temperatures and hydrogen partial pressures, $300-400{ }^{\circ} \mathrm{C}$ and 20 - $100 \mathrm{~atm}$ of hydrogen, respectively,. These extremely demanding operating conditions make this process very costly in particular when high molecular weight and more stable sulphur compounds are present in the fuel, requiring higher residence time and more severe operating conditions. [1] Concerning the sulphur species, they can be aliphatic and aromatic and are mainly classified as thiols, sulphides and thiophenes. Thiols (aliphatic sulphur compounds) can also be removed by a sweeting process known as Merox $\AA$, where a liquid-liquid extraction with caustic soda is aided with a catalytic oxidation by air. For heavier fractions, this process becomes more difficult and fixedbed sweetening alternatives are used. As the environmental and legal specifications increased stringently and aim at the use of ultra-low sulphur fuels $(<10 \mathrm{ppm} \mathrm{S})$, the production of these fuels is more challenging since nowadays crude oils present higher sulphur contents and lower quality. In order to overcome the inefficient conventional desulphurization, researchers directed their works towards new alternative methods. Separation processes such as extraction and oxidation, adsorption and bioconversion have been considered, along with their combinations. [2-8]

Many of these alternative processes use ionic liquids as solvents. Their negligible volatility, liquid state in a large range of temperatures and tuneable solvation towards polar and non-polar compounds turn ionic liquids into very attractive extracting solvents allowing their use at high temperatures while maintaining chemical and thermal stability. [9] Additionally, the possibility of a simple regeneration of the ionic liquid and its reuse in the extraction process permits a more sustainable management. [1]

Regarding the extraction of thiols (aliphatic sulphur species) from "jet-fuel" streams, our previous work [10] showed the high potential of ionic liquids as extracting solvents, despite the low thiol affinity towards the ionic liquids. This feature makes the conventional liquid-liquid extraction not viable due to the high volumes of extracting 
ionic liquid that would be required. However, the ionic liquids studied and $n$-dodecane, used as the "jet-fuel" model, presented almost negligible mutual solubility, which avoids mutual contamination and losses of fuel and ionic liquid in the separation process. For this reason, the use of ionic liquids as solvents is potentially interesting, as discussed in our previous work,[10] where supported ionic liquid membranes (SILMs) were studied. SILMs were evaluated for the selective extraction of a thiol target solute applying vacuum in the downstream side, in order to benefit from the very low mutual solubility between the aliphatic compounds and the ionic liquids. Though, it was observed a significant permeation of $n$-dodecane through the SILM polymeric support. This problem was overcome using the ionic liquid as a receiving phase and no dodecane was detected, opening opportunities for new approaches. This extraction process experiment was carried out in a hollow fibre membrane contactor, in a counter-currentflow mode.

Hollow fibre membrane contactors have proven to be very advantageous in separation processes, as shown by the large variety of systems tested in both liquid and gas separations, [11-18] including thiols removal from a simulated naphtha stream under a reactive extraction with an aqueous $\mathrm{NaOH}$ solution [19, 20]. ENREF_14Membrane contactors provide large interfacial area between the two contacting phases, through the pores of the membrane, not requiring density differences and dispersion between the two phases. Consequently, back-mixing and formation of stable emulsions are prevented. Additionally, each fluid phase can be independently operated within a wide range of flow rates. $[15,18,21,22]$

The present work addresses the study of an integrated process using hydrophobic hollow fibre membrane contactors of polypropylene, where the selective thiol extraction occurs in a first membrane contactor and, simultaneously, regeneration takes place in a second contactor aiming at a complete removal of the thiol from the ionic liquid. This configuration offers several advantages, such as the reuse of the ionic liquid in the extraction process, by recirculation in a closed loop between the two membrane contactors. Therefore, the volume of ionic liquid required is much lower than in conventional equipment. Moreover, the driving force for solute transport is maximized, which is particularly important when the partitioning of the target solute is not thermodynamically favoured. The ionic liquid regeneration can be performed by different techniques, such as direct distillation, [23-26] evaporation, [27-29] reextraction by an organic or aqueous solvent [30-32] or by using supercritical carbon dioxide [33-35], membrane separation, [36-38]_ENREF_8 stripping with a sweep gas or vacuum, with or without thermal treatment, [39-43] or by a combination of methods. 
In this work, stripping applying vacuum and by using a sweep gas in the downstream of the membrane compartment were studied for the regeneration of the ionic liquid.

\section{Experimental Section}

The membrane contactors experiments were carried out using three different configurations in order to study the most promising set-up for the thiols removal from a jet-fuel model mixture. The configurations tested were: single extraction, simultaneous extraction and stripping with vacuum, and simultaneous extraction and stripping by using a sweep gas.

The most suitable ionic liquid to be used in the extraction of thiols from a jet-fuel supply should present high affinity to the target compound and low mutual solubility with other feed compounds, avoiding their co-extraction [44], and should present high mass transfer kinetics coefficients. Based on our previous work [10] on liquid-liquid equilibrium and mass transfer kinetics in a classical liquid-liquid extraction process, the ionic liquid that was identified to fulfil these separation requirements was the 1-ethyl-3methylimidazolium triflate, $\left[\mathrm{C}_{2} \mathrm{mim}\right]\left[\mathrm{CF}_{3} \mathrm{SO}_{3}\right]$ [44].

To perform these experiments, two hollow fibre membrane contactors with porous polypropylene membranes were selected based on their wetting properties. These hydrophobic membranes are not easily wetted by the selected ionic liquid [10]. Therefore, in the first extraction contactor, the membranes pores are wetted and filled with the $n$-dodecane phase, while in the stripping contactor, the pores are filled by air (both in the case of the vacuum stripping and the sweep gas stripping). This selection of an hydrophobic material allows, therefore, to minimize the mass transfer resistance for solute transport through the membrane area. Additionally, given the positive thiol partition towards the hydrocarbon feed, it is also favourable to have the feed wetting the membrane pores, instead of the ionic liquid.

\subsection{Materials}

The jet-fuel feed solution is composed by the hydrocarbon $n$-dodecane and circa $1 \%$ of the thiol 1-hexanethiol, which were acquired from Sigma-Aldrich, with 99\% and 95\% purity, respectively.

The $\left[\mathrm{C}_{2} \mathrm{mim}\right]\left[\mathrm{CF}_{3} \mathrm{SO}_{3}\right]$ ionic liquid was acquired from loLiTec, lonic Liquid Technology, Germany, with purity superior to $99 \%$ and, before use, it was vacuum dried ( $1 \mathrm{mPa})$ at $313.2 \mathrm{~K}$, under constant stirring for a minimum of $24 \mathrm{~h}$. 
The sweep gas selected to perform the re-extraction of the thiol from the ionic liquid was compressed air, since it is the most economic option.

The membrane contactors used were supplied by Membrana $\mathrm{GmbH}$, Germany. The single extraction and the extraction stage in the integrated configurations were carried out in a Liqui-cel MiniModule ${ }^{\circledR}$ Contactor, while for the ionic liquid regeneration stage, either by vacuum or sweep gas, it was used a Liqui-cel ExtraFlow ${ }^{\circledR}$ Contactor. Both modules comprise microporous polypropylene hollow fibre membranes by Celgard ${ }^{\circledR}$, Hoechst Celanese, Germany. In the case of the MiniModule ${ }^{\circledR}$ the membranes are Celgard $^{\circledR}$ X-10, while for the ExtraFlow ${ }^{\circledR}$, it was used the Celgard ${ }^{\circledR}$ X-50 type fibres. Additional information about the membrane contactors and fibres can be accessed in Table 1.

Table 1 Characteristics of the laboratory Liqui-cel MiniModule ${ }^{\circledR}$ and Extra-flow Modul ${ }^{\circledR}$ Contactor, and respective hollow fibres properties, Celgard X-10 and Celgard $\mathrm{X}-50$.

\begin{tabular}{ccc}
\hline Module & Mini-module & Extra-flow \\
\hline Shell inner diameter $(\mathrm{cm})$ & 2.5 & 6.6 \\
Length $(\mathrm{cm})$ & 20 & 28 \\
Effective area $\left(\mathrm{m}^{2}\right)$ & 0.23 & 1.4 \\
Specific area $\left(\mathrm{cm}^{2} / \mathrm{cm}^{3}\right)$ & 40 & 40 \\
Number of fibres & 2100 & 10200 \\
\hline Membrane fibre & Celgard X-10 & Celgard X-50 \\
\hline Internal diameter $(\mu \mathrm{m})$ & 240 & 220 \\
External diameter $(\mu \mathrm{m})$ & 300 & 300 \\
Porosity $(\%)$ & 30 & 40 \\
Effective pore size $(\mu \mathrm{m})$ & 0.05 & 0.04 \\
Pore dimensions $(\mu \mathrm{m})$ & $0.05 \times 0.15$ & Not available \\
Effective fibre length $(\mathrm{cm})$ & 16 & 16 \\
\hline
\end{tabular}

\subsection{Experimental procedure}

The membrane contactor experimental set-up, for the single extraction of 1-hexanethiol from the model feed stream, is depicted in Figure 1. A second membrane contactor was coupled to the extraction module to perform the ionic liquid regeneration, either by applying vacuum or a sweep gas, as can also be seen in Figure 1. 
Closed vessels $(500 \mathrm{~mL})$ with small headspaces were used in order to minimize the loss of the feed compounds to the atmosphere and variations of phase volume and concentration.

In the extraction module the feed was pumped into the shell side, while the ionic liquid extracting phase was circulated in counter-current inside the hollow fibres (lumen side). This operating mode was selected due to the different viscosities of the fluids, being thirty times higher for the ionic liquid $\left[\mathrm{C}_{2} \mathrm{mim}\right]\left[\mathrm{CF}_{3} \mathrm{SO}_{3}\right]$ compared with the hydrocarbon feed. Therefore, circulating the ionic liquid in the lumen side allowed for a better fluid hydrodynamics and avoided channelling volumes that could easily occur in the shell side. For this reason, the ionic liquid was also circulated in the lumen side of the regeneration module.

In order to assure appropriate starting conditions, all independent experiments started by circulating the ionic liquid in the lumen side and, only after completion of this procedure, the feed stream was then circulated in the shell side. This procedure assured that no feed stream was able to permeate through the pores to the lumen side (remember that the membrane used is hydrophobic and, therefore, wetted by the $n$ dodecane feed).

The higher viscosity of the ionic liquid promoted a slight overpressure on the lumen side, which also helped to obtain a more stable interface between the feed and the ionic liquid in the extraction module. For the integrated process, the same procedure was adopted, circulating the ionic liquid in each contactor before introducing the feed in the extraction contactor in order to reduce the delay related with the regeneration of the ionic liquid.

During all experiments, representative samples of the feed and ionic liquid phases $(0.3$ $-0.5 \mathrm{ml}$ ) were collected and analysed along time.

During the experiments, the flow-rate of each fluid was controlled by magnetic drive gear pumps (Ismatec, Switzerland), and measured using variable area flowmeters at the exit of the contactor. These pumps allowed for eliminating flow-rate oscillations and pulsating effects. During the experiments, the pressures at the inlet and outlet of the shell and lumen were also measured with analogical manometers. To achieve a better control of the operation temperature, the feed and ionic liquid reservoirs and the membrane contactor were jacketed by circulating thermo-regulated water using a thermostat bath (Julabo MC), with a temperature stability of $\pm 0.01 \mathrm{~K}$. The temperature in the vessels was measured using a thermometer $( \pm 0.1 \mathrm{~K})$. 


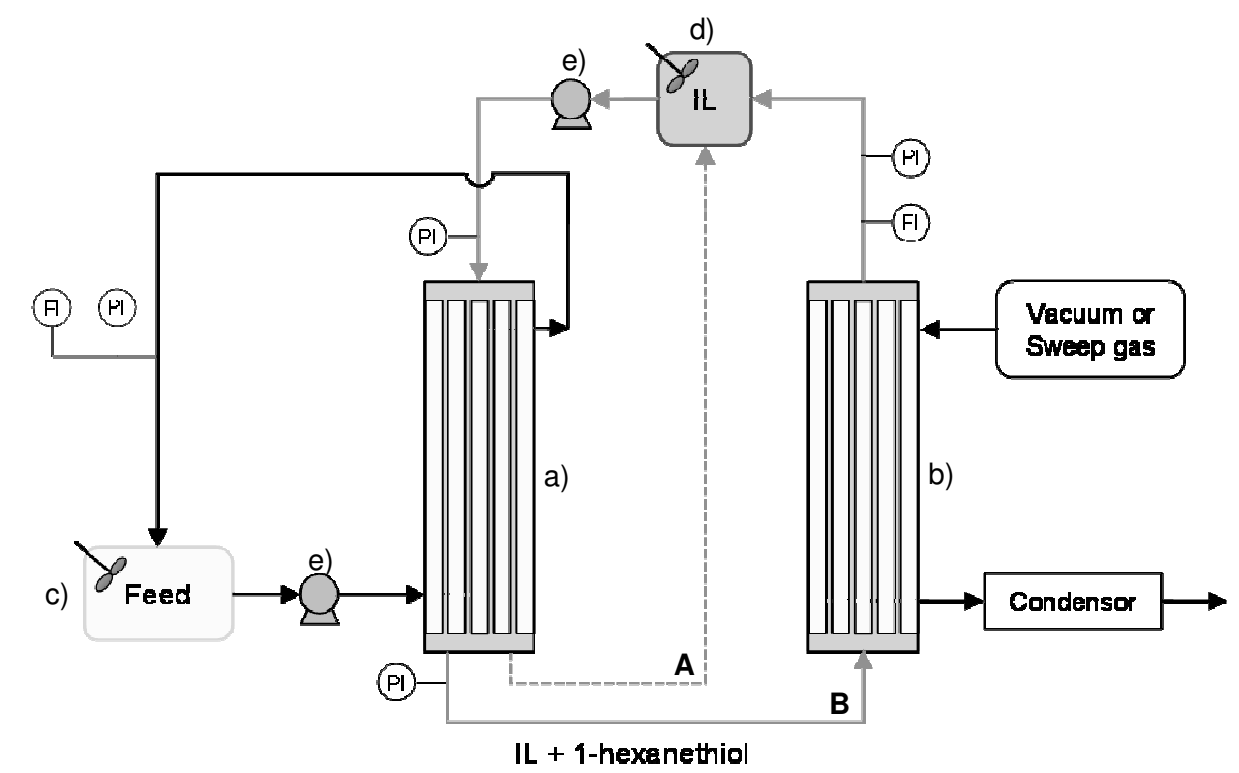

Figure 1 Experimental set-up. A indicates the ionic liquid direction in the single extraction configuration, and $\mathbf{B}$ in the integrated extraction and regeneration configuration. a) extraction hollow fibre membrane contactor, b) regeneration hollow fibre membrane contactor, c) feed stirred vessel, d) ionic liquid stirred vessel, e) recirculating pump, $\mathrm{PI}$ = pressure indicator, and $\mathrm{FI}=$ flow indicator.

\subsection{Operating conditions}

All experiments for the study of the removal of thiols were carried out under controlled operating conditions. It was decided to operate at a temperature of $298.15 \pm 0.2 \mathrm{~K}$. However, as discussed later in this work, higher operating temperatures were also considered and their potential impact was simulated, supported on the knowledge about their effect in viscosity and diffusion coefficient of the target solute.

For all configurations studied, the modules were operated in a counter-current mode in order to guarantee the highest possible mass transfer.

In terms of selection of the stream flow rates, some precautions were considered: it was assured that the pressure drop inside the membrane fibres does not overcome the pores' breakthrough pressure (minimum pressure required to force the ionic liquid into the membrane pores), in order to maintain a stable interface between the ionic liquid phase and the feed phase. 
The breakthrough pressure $\left(\Delta P_{c r}\right)$ of the $\left[\mathrm{C}_{2} \mathrm{mim}\right]\left[\mathrm{CF}_{3} \mathrm{SO}_{3}\right]$ ionic liquid for the system polypropylene $+n$-dodecane and was determined using the Young-Laplace equation [17]:

$\Delta P_{c r}=\frac{2 \gamma \cos \theta}{r_{\text {pore }}} \times 10^{-5}$ bar

For the interfacial tension $(\gamma)$ determination, it was assumed, that the low concentration of the thiol in the feed phase does not have a significant impact on the interfacial tension. Thus, the interfacial tension measured between the $n$-dodecane and the $\left[\mathrm{C}_{2} \mathrm{mim}\right]\left[\mathrm{CF}_{3} \mathrm{SO}_{3}\right]$, at $298.15 \mathrm{~K}$, by the du Nouy ring method using a Attension Sigma 702ET, was of $15.2 \mathrm{mN} \cdot \mathrm{m}^{-1}$. The contact angle between the ionic liquid and the polypropylene membrane $\theta$ has the value of $121^{\circ}(2.11 \mathrm{rad})$. The $r_{\text {pore }}$ is the pore radius $(\mathrm{m})$, assuming parallel cylindrical pores.

Taking into account the ellipsoidal shape of the pores of the membrane Celgard X-10, an average breakthrough pressure of 3.85 bar was obtained. Therefore pressures differences up to 3.85 bar can be applied without interface disturbance and ionic liquid penetration inside the membrane pores. Experimentally, the flow rate of the ionic liquid in the lumen side of both contactors, was set at $0.96 \mathrm{~cm}^{3} / \mathrm{s}$ for all experiments. Under these conditions, the inlet pressure for the ionic liquid side was observed to be at 0.65 bar during the single extraction experiments, and between 0.70 bar to 0.75 bar for the integrated configuration, to assure a stable interface. The outlet pressures were kept at atmospheric pressure and 0.2 bar, respectively, for the single extraction and the integration operation. This last value of outlet pressure corresponded to the inlet pressure in the regeneration contactor.

For the feed flow, circulating in the shell side of the extraction contactor, it was set at a flow-rate of $6.5 \mathrm{~cm}^{3} / \mathrm{s}$. The operating pressures for the feed phase, in the extraction module, were lower than 0.05 bar at the inlet, and in its exit was atmospheric pressure. From these pressures values, the membrane pressure differences varied from 0.7 to 0.0 bar, due to the pressure drop observed along the lumen side, quite below the estimated breakthrough pressure.

The fluid velocity for the feed phase, considering the hydraulic diameter, is $1.90 \mathrm{~cm} . \mathrm{s}^{-1}$, and for the ionic liquid phase, the velocities varied between $1.01 \mathrm{~cm} . \mathrm{s}^{-1} 1$ and $1.04 \mathrm{~cm} . \mathrm{s}^{-1}$ in the extraction module and between $0.248 \mathrm{~cm} . \mathrm{s}^{-1}$ and $0.255 \mathrm{~cm} . \mathrm{s}^{-1}$ in the regeneration module. 
In the integrated set-up, vacuum or sweep gas were applied at the module shell side. The experiments started by testing vacuum at a pressure of 1 mbar. For the experiments carried out using the sweep gas, compressed air flow rates of $1.23 \mathrm{~cm} . \mathrm{s}^{-1}$, $7.84 \mathrm{~cm} . \mathrm{s}^{-1}$ and $19.30 \mathrm{~cm} . \mathrm{s}^{-1}$ were tested to study its impact in the mass transfer.

The membrane contactors were cleaned after each experiment in order to maintain the same initial conditions. The washing procedure consisted in removing the highest amount of the solvents without using any external agents. Then, water was added to the lumen side for removing the ionic liquid and, in the feed side, isopropanol helped to eliminate the hydrocarbon compounds. This procedure was repeated two to three times and then compressed air was passed through the system until it was completely dried and free of solvents.

\subsection{Analytical methods}

The concentration of the model thiol compound was measured in each stream by a potentiometric titration, using a TitraLab® 865 titration workstation, with an alcoholic solution of $\mathrm{AgNO}_{3}$ at $0.01 \mathrm{M}$, according to the ASTM D3227 standard [45]. The ionic liquid content in the feed phase was analysed by UV spectroscopy, using a Helios $\alpha$ UV-Vis spectrophotometer from Thermo Scientific, though no peaks corresponding to the ionic liquid were found, assuring that no contamination of the feed stream by the ionic liquid took place (at least, not above the detection limit). The $n$-dodecane content in the ionic liquid stream was determined gravimetrically $\left( \pm 10^{-4} \mathrm{~g}\right)$ using a vacuum drying process and was found negligible. Nevertheless, even considering that the contents of ionic liquid in $n$-dodecane and of $n$-dodecane in ionic liquid-rich streams are insignificant, it must be keep in mind that traces of these compounds can occur at concentrations below the detection threshold. 


\section{Mass transfer model}

In order to model the extraction of 1-hexanethiol from the feed stream into the ionic liquid phase in the all the configurations tested, single extraction and integrated extraction/stripping, a material balance was performed to the membrane contactor and vessel.

Considering the extraction module and assuming equilibrium at the feed/ionic liquid interface, the differential mass balance is described as:

$$
-Q_{f} \frac{d C_{f}}{d A_{M}}=K_{f}\left(C_{f}-C_{f}^{*}\right)
$$

where $Q_{f}\left(\mathrm{~m}^{3} \cdot \mathrm{s}^{-1}\right)$ is the feed flow rate, $C_{f}$ and the $C_{f}^{*}\left(\mathrm{~mol} . \mathrm{m}^{-3}\right)$ are the 1-hexanethiol concentration in the phase under consideration and in equilibrium with the 1hexanethiol concentration in the other phase. $K_{f}$ represents the overall mass transfer coefficient $\left(\mathrm{m} \cdot \mathrm{s}^{-1}\right)$, and $A_{M}=\pi d_{f i} L_{f} N_{f}\left(\mathrm{~m}^{2}\right)$ the module membrane area, where $d_{f i}$.is the internal fibre diameter $(\mathrm{m}), L_{f}$ is the fibre length $(\mathrm{m})$ and $N_{f}$ the number of fibres in the membrane contactor.

The differential mass balance to the feed fluid vessel can be written as:

$$
-V_{f} \frac{d C_{f}}{d t}=Q_{f}\left(C_{f}^{\text {out }}-C_{f}^{\text {in }}\right)
$$

where $V_{f}\left(\mathrm{~m}^{3}\right)$ is the feed phase volume, $C_{f}^{\text {in }}$ and $C_{f}^{\text {out }}\left(\mathrm{mol}^{-3}\right)$ are the inlet and outlet 1-hexanethiol concentrations in the membrane contactor. The operating time is defined by $t$ (s).

Since the feed stream is operated with recirculation and assuming that the driving force variation in a single passage over the membrane contactor can be assumed negligible for the small interfacial area, $A_{E}\left(0.23 \mathrm{~m}^{2}\right)$, and the fluid vessels have a high degree of mixture, which turns the thiol concentration in the feed vessel equal to the inlet concentration of the module, equations 2 and 3 can be combined in the following equation:

$$
-V_{f} \frac{d C_{f}}{d t}=K_{f} A_{E}\left(C_{f}-C_{f}^{*}\right)
$$

The $C_{f}^{*}$ is related with the 1 -hexanethiol concentration in the ionic liquid rich phase ( $C_{I L}$ ) applying the distribution ratio $(D)$ definition: 


$$
C_{f}^{*}=\frac{C_{I L}}{D}
$$

The distribution ratio was determined in a previous work [10] and a value of 0.095 \pm 0.026 for the system $\left[\mathrm{C}_{2} \mathrm{mim}\right]\left[\mathrm{CF}_{3} \mathrm{SO}_{3}\right]+1$-hexanethiol $+n$-dodecane was obtained.

For the single extraction process, the concentration $C_{I L}$ is obtained from a simple mass balance to the solute, at the initial conditions, in the feed phase and ionic liquid phase, $C_{f}^{0}$ and $C_{I L}^{0}$, respectively:

$C_{I L}=\frac{V_{f}}{V_{I L}}\left(C_{f}^{0}-C_{f}\right) \quad t=0, C_{f}=C_{f}^{0}, C_{I L}=C_{I L}^{0}=0$

The overall mass transfer coefficient, $K_{f}$, is determined by fitting the experimental thiol concentration in function of time with the integration of equations 4,5 and 6 , considering the initial conditions.

In the case of the integrated process, when applying regeneration by sweep gas, a differential material balance to the ionic liquid must also be done, to a more accurate description of the solute mass transport in this stream:

$$
V_{I L} \frac{d C_{I L}}{d t}=K_{E} A_{E}\left(C_{f}-C_{f}^{*}\right)-K_{R} A_{R}\left(C_{I L}-C_{I L}^{*}\right)
$$

In this equation, $K_{E}$ and $K_{R}$ are the overall mass transfer coefficients associated with each module of the integrated process, extraction and regeneration, with the respective membrane areas $A_{E}$ and $A_{R}$. Here, $C_{I L}^{*}$ is the concentration of thiol in the ionic liquid in equilibrium with its concentration in the gaseous phase $\left(C_{g}\right)$ inside the pore of the membrane ( $C_{I L}^{*}=\frac{C_{g}}{H}, H=$ Henry's constant). The value of $H$ was estimated [46] by the product of the vapour pressure of 1-hexanethiol at the operating temperature $(298.15 \mathrm{~K})$ and the activity coefficient at infinite dilution. The $H$ value was calculated to be $0.0022\left(\mathrm{~mol} . \mathrm{m}^{-3} / \mathrm{mol}^{-3} \mathrm{~m}^{-3}\right.$.

By a material mass balance to the system, the thiol concentration in the gas phase can be described as:

$$
C_{g}=\frac{V_{f}\left(C_{f}^{0}-C_{f}\right)-C_{I L} V_{I L}}{t Q_{g}} \quad t=0, C_{f}=C_{f}^{0}, C_{I L}=C_{I L}^{0}=0, C_{g}=C_{g}^{0}=0
$$


Considering an efficient regeneration process where the thiol is completely removed from the ionic liquid $\left(C_{I L} \approx 0 \mathrm{~mol} . \mathrm{m}^{-3}\right)$, and assuming the extraction process as the limiting stage of the integrated process, the overall mass transfer can be determined by fitting the experimental thiol concentration of the feed phase with equation 4 for $C_{I L}^{*}=0$

The resistances-in-series model, based on the combination of the individual mass transfer resistances, is helpful understanding the thiol extraction/stripping process.

Equations 9 and 10 describe the resistances in the extraction and regeneration modules, respectively:

$$
\begin{gathered}
\frac{1}{K_{E}}=\frac{d_{i, E}}{d_{o, E} k_{f}}+\frac{d_{i, E}}{d_{l m, E} k_{M_{f}}}+\frac{1}{D k_{I L, E}} \\
\frac{1}{K_{R}}=\frac{d_{i, R}}{d_{o, R} k_{g} H}+\frac{d_{i, R}}{d_{l m, R} k_{M_{g}} H}+\frac{1}{k_{I L, R}}
\end{gathered}
$$

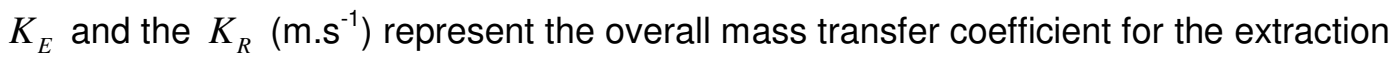
and the regeneration process, respectively. In terms of the individual mass transfer coefficients, they are described by $k_{f}, k_{I L, E}, k_{I L, R}$ and $k_{g}\left(\mathrm{~m} . \mathrm{s}^{-1}\right)$ for the boundary films associated with the feed, the ionic liquid and the gaseous phase, respectively. The $d_{i}$, $d_{o}$ and $d_{l m}(\mathrm{~m})$ are the inner, outer and logarithmic mean fibre diameters in the extraction and regeneration modules.

The mass transfer coefficients associated with transport through the membrane in each module are the $k_{M_{f}}$ and $k_{M_{g}}\left(\mathrm{~m}_{\mathrm{s}} \mathrm{s}^{-1}\right)$ and are determined accordingly with the phase wetting the membrane:

$k_{M_{f}}=\frac{\mathfrak{D}_{M f} \varepsilon_{M, E}}{\delta_{M, E} \tau_{M, E}}$ and $k_{M_{g}}=\frac{\mathfrak{D}_{M g} \varepsilon_{M, R}}{\delta_{M, R} \tau_{M, R}}$

where $\mathfrak{D}$ is the diffusion coefficient $\left(\mathrm{m}^{2} \cdot \mathrm{s}^{-1}\right)$ at a $T$ temperature $(\mathrm{K}) ., \mathcal{E}, \delta$ and $\tau$ are the porosity, thickness $(\mathrm{m})$ and tortuosity of the membrane, in the extraction $(E)$ and regeneration $(R)$ modules. 
As shown in our previous work, [10] due to the high ionic liquid viscosity and low thiol diffusion in the ionic liquid, the ionic liquid phase presents the highest mass transfer resistance to the transport of thiol. Moreover, since the membranes in the extraction and regeneration modules are wetted by the feed and gas phases (not-controlling phases), respectively, the resistance in series equations can be simplified to the resistance in the ionic liquid boundary film.

\section{Calculation methods}

The fitting of the thiol concentration variation with time, for the various experiments were performed using the nlinfit routine, from the software package Matlab ${ }^{\mathrm{TM}}$, from Math Works Inc. (USA). The overall mass transfer coefficients for the single extraction process and for the integrated process were determined by performing a nonlinear regression, using the iterative least squares algorithm, and simultaneously solving the differential equations system previously specified for each configuration. The parameters' errors were calculated within a 95\% confidence interval.

\section{Results and discussion}

The liquid extraction process using membrane contactors is explored using a mixture of 1-hexanethiol and $n$-dodecane, as jet-fuel model feed, and the ionic liquid $\left[\mathrm{C}_{2} \mathrm{mim}\right]\left[\mathrm{CF}_{3} \mathrm{SO}_{3}\right]$. This ionic liquid was selected in order to avoid the co-extraction of $n$ dodecane and other fuel compounds.

The methodology followed in this work involved a pre-evaluation of the membrane contactor applicability in the extraction process, followed by its integration with a regeneration step aiming re-extracting the target solute from the ionic liquid, and reuse of the ionic liquid in the extraction module, in a closed loop.

\subsection{Single extraction in a membrane contactor}

The 1-hexanethiol extraction was firstly studied in a single membrane contactor and the experimental data is plotted in Figure 2. The 1-hexanethiol concentration profile obtained is very regular and smooth, reaching equilibrium at circa $1.5 \mathrm{~h}$ of operation time. Comparing this profile with the profile obtained in mass transfer studies in an extraction cell, previously reported, [10] it was found that these extraction profiles present the same behaviour, except for the time needed to reach equilibrium, due to the different interfacial areas available for mass transfer. As expected, the mass transfer rate was faster using the membrane contactor, due to a higher interfacial area 
of $0.23 \mathrm{~m}^{2}\left(3225 \mathrm{~m}^{2} / \mathrm{m}^{3}\right)$ assured by the membrane contactor, against the $0.0002 \mathrm{~m}^{2}$ $\left(20 \mathrm{~m}^{2} / \mathrm{m}^{3}\right)$ available in the stirred extraction cell.

Regarding the overall mass transfer coefficient for this single extraction, the experimental concentration data were fitted considering equations 4,5 and 6 and the value obtained was $7.88 \pm 0.35 \times 10^{-8} \mathrm{~m} \cdot \mathrm{s}^{-1}$, which can be considered relatively low when comparing with other extraction systems using this type of equipment.

Though the low mass transfer rate, the thiol extraction using the selected ionic liquid shows a high potential since, as a result of the very low mutual solubility between the ionic liquid and the $n$-dodecane, no $n$-dodecane was detected in the ionic liquid phase. The ionic liquid worked as a liquid barrier to the transport of the $n$-dodecane and the undesirable co-extraction of the fuel compounds was prevented.

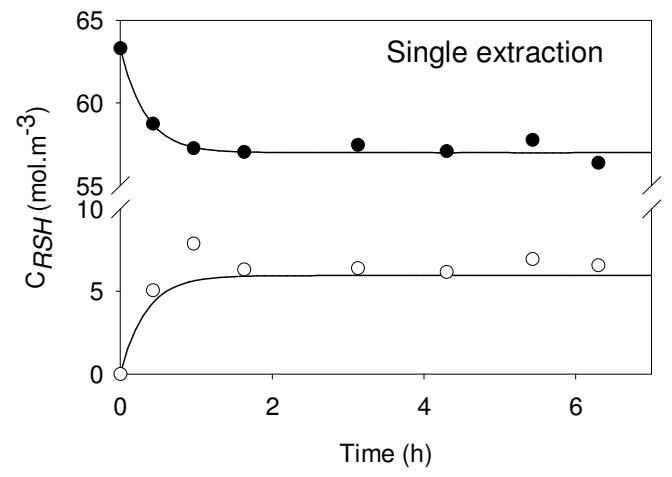

Figure 2 1-hexanethiol experimental concentration profile in the $n$-dodecane and ionic liquid rich-phases (filled and empty symbols, respectively), and data fitting (lines), for the single extraction configuration, at $298.2 \mathrm{~K}$ and atmospheric pressure. Extraction module: shell side - jet-fuel model stream (1-hexanethiol + $n$-dodecane); lumen side ionic liquid $\left(\left[\mathrm{C}_{2} \mathrm{mim}\right]\left[\mathrm{CF}_{3} \mathrm{SO}_{3}\right]\right)$.

\subsection{Simultaneous extraction and regeneration in membrane contactors}

The following experiments aim at evaluating the regeneration technique more suitable to be integrated with the extraction unit (Figure 1). The first experiment consisted in testing the use of vacuum in the shell side of the second contactor to strip the thiol from the ionic liquid stream. The second approach used a sweep gas stream also circulated in the shell side. In these experiments, the ionic liquid stream was operated in a closed loop, between the extraction and the regeneration contactors, and the effect of the regeneration process was monitored by analysing the thiol concentration variation in the jet-fuel feed phase. 


\subsubsection{Vacuum-based regeneration}

The regeneration with vacuum was performed at 1 mbar and room temperature to allow the evaporation of 1-hexanethiol at $298.2 \mathrm{~K}$ under vacuum, which has a vapour pressure around 6 mbar at this temperature. The experimental concentrations of thiol in the feed and the ionic liquid phase are plotted in Figure 3.

As can be observed from the thiol extraction results, its extraction from the feed stream stops after $2 \mathrm{~h}$ and tends to a constant value. The use of vacuum does not have a positive impact on the extraction of the target solute and, therefore, cannot be considered as a potential process for the re-extraction of thiols from the ionic liquid extractant. This unfavourable behaviour results from the partial penetration of the ionic liquid inside the pores of the polypropylene membrane. Under these circumstances, the ionic liquid wets the pores of fibres creating an additional significant mass transfer resistance to the process of solute transfer. This additional resistance cannot be neglected since the ionic liquid has a high viscosity (41 mPa.s). Consequently, the transport of thiol by diffusion from the ionic liquid phase to the vacuum phase becomes extremely slow. This negative effect on the overall mass transfer of solute does not allow for an effective regeneration of the extractant in a short operating time. This problem was difficult to anticipate, since the ionic liquid has a negligible vapour pressure and, from our previous work [10], the polypropylene membrane tested is not easily wetted by the $\left[\mathrm{C}_{2} \mathrm{mim}\right]\left[\mathrm{CF}_{3} \mathrm{SO}_{3}\right]$ ionic liquid. The continuous application of vacuum in the downstream circuit might force its partial penetration into the pores of the polypropylene membrane, reducing the mass transfer rate.

The average breakthrough pressure of 3.85 bar previously calculated refers to the pressure required for the ionic liquid penetration into the pores of the fibre membrane of polypropylene wetted by $n$-dodecane. In that case a n-dodecane / ionic liquid interfacial tension is involved. This value cannot be used straightforward when the system under study involves an ionic liquid / vacuum interface, where the ionic liquid partial penetration within the membrane pores may occur.

Taking this result into consideration, it was decided to evaluate the removal of the thiol compound from the ionic liquid phase by applying a sweep gas stream, avoiding the displacement of the ionic liquid to the pores of the membrane. 


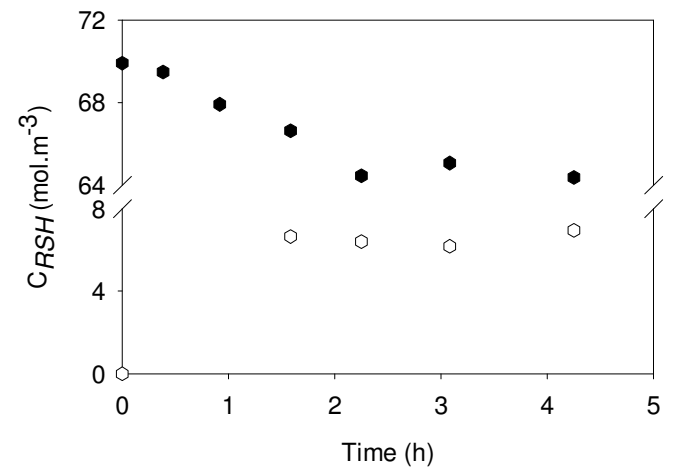

Figure 3 1-hexanethiol experimental concentration profile in the $n$-dodecane and ionic liquid phases (filled and empty symbols, respectively), for the extraction/vacuum stripping configuration, at $298.2 \mathrm{~K}$ and atmospheric pressure. Extraction module: shell side - jet-fuel model stream (1-hexanethiol + $n$-dodecane); lumen side - ionic liquid $\left(\left[\mathrm{C}_{2} \mathrm{mim}\right]\left[\mathrm{CF}_{3} \mathrm{SO}_{3}\right]\right)$. Regeneration module: shell side - vacuum; lumen side - ionic liquid $\left(\left[\mathrm{C}_{2} \mathrm{mim}\right]\left[\mathrm{CF}_{3} \mathrm{SO}_{3}\right]\right)$.

\subsubsection{Sweep-gas based regeneration}

As an alternative to vacuum regeneration, a sweep gas stream of compressed air was used in the downstream circuit of the second membrane contactor, aiming an efficient cleaning of the ionic liquid. This unit worked under gentle conditions of temperature and pressure, avoiding the permeation of the ionic liquid through the membrane.

Three sweep gas flow-rates were tested with linear velocities from $1.23 \mathrm{~cm} . \mathrm{s}^{-1}$ to 19.30 $\mathrm{cm} . \mathrm{s}^{-1}$ and their impact on the thiol extraction is shown in Figure 4. Comparing the results obtained, it is possible to observe that the use of sweep gas allows overcoming the unfavourable low thermodynamic equilibrium observed in the single extraction (Figure 2), since it was possible to reduce the thiol concentration in the feed stream to values very close to zero, i.e. lower than $2 \mathrm{ppm}$, as targeted by the legislation. This result proves the high potential of this integrated process as an alternative method to the deep-desulphurization process. This process not only allows the production of ultralow sulphur fuels, but also allows reducing the operating costs due to the mild conditions of temperature and pressures applied.

In what concerns the mass transfer occurring in these processes, a significant variation of the thiol concentration in the ionic liquid phase is observed for different experiments. It is shown that the increase of the sweep gas flow rate leads to a more efficient removal of thiol from the ionic liquid and to a consequent improvement of the extraction of the thiol from the feed stream. This increase of the gas velocity in the shell side of 
the module reduces the residence time of the gas inside the membrane contactor, which increases the driving force for mass transfer by lowering the concentration of this solute in the gaseous phase.

The effect of increasing the velocity of the sweep gas on the extraction process is important up to a point where a complete re-extraction of the thiol from the ionic liquid is achieved. For higher sweep gas flow-rates (lower residence time), at which the regeneration is complete, the integrated process becomes controlled by the extraction of the thiol from the feed phase. 

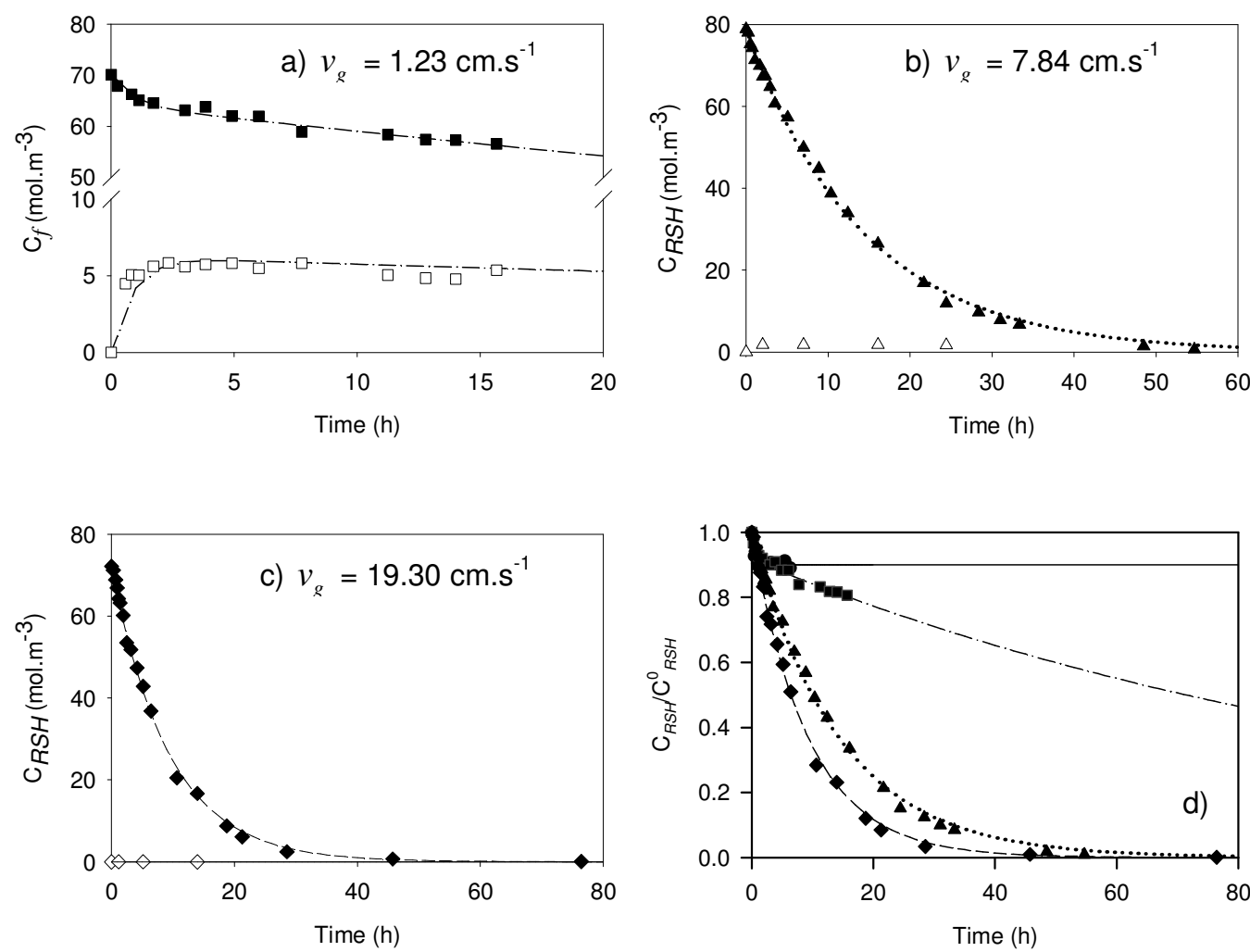

Figure 4 1-hexanethiol experimental concentration profile in the $n$-dodecane and ionic liquid phases (filled and empty symbols, respectively) and data fitting (lines), for the extraction/sweep gas stripping configurations, at $298.2 \mathrm{~K}$ and atmospheric pressure, with a) sweep gas velocity of $1.23 \mathrm{~cm} . \mathrm{s}^{-1}$ (square symbols and dot-dashed lines), b) sweep gas velocity of $7.84 \mathrm{~cm} . \mathrm{s}^{-1}$ (triangle symbols and dotted lines) and c) sweep gas velocity of $19.30 \mathrm{~cm} . \mathrm{s}^{-1}$ (diamond symbols and dashed lines).

Extraction module: shell side - jet-fuel model (1-hexanethiol + $n$-dodecane); lumen side - ionic liquid ([ $\left.\left.\mathrm{C}_{2} \mathrm{mim}\right]\left[\mathrm{CF}_{3} \mathrm{SO}_{3}\right]\right)$. Regeneration module: shell side - sweep gas; lumen side - ionic liquid $\left(\left[\mathrm{C}_{2} \mathrm{mim}\right]\left[\mathrm{CF}_{3} \mathrm{SO}_{3}\right]\right)$. And $\mathbf{d}$ ) comparison between the single extraction (solid line) and the three extraction/sweep gas stripping systems studied (dodecane phase).

\section{Mass transfer kinetics}

For the case of the lower sweep gas flow rate $\left(v_{g}=1.23 \mathrm{~cm} \cdot \mathrm{s}^{-1}\right)$, where the thiol concentration in the ionic liquid stream remains considerable, the overall mass transfer coefficient was calculated by fitting the experimental thiol concentration profile with equations $4,5,7$ and 8 . 
The extraction and regeneration mass transfer coefficients determined were $4.90 \pm$ $1.49 \times 10^{-8} \mathrm{~m} . \mathrm{s}^{-1}$ and $1.06 \pm 0.20 \times 10^{-8} \mathrm{~m} . \mathrm{s}^{-1}$, respectively. Knowing that the dominant resistance in each module is the transport of the thiol in the ionic liquid phase, these values should be equal if the fluid dynamics of the ionic liquid phase in both modules were identical. The difference observed results from the different ionic liquid stream velocity rates: $1.01 \mathrm{~cm} . \mathrm{s}^{-1}$ in the extraction module and $0.248 \mathrm{~cm} . \mathrm{s}^{-1}$ in the regeneration module.

For the experiments with $v_{g}=7.84 \mathrm{~cm} . \mathrm{s}^{-1}$ and $v_{g}=19.30 \mathrm{~cm} \cdot \mathrm{s}^{-1}$, the thiol concentration remaining in the ionic liquid phase was extremely low, practically zero $\left(0.04 \mathrm{~mol} . \mathrm{m}^{-3}\right.$ and below the detection threshold, respectively), due to a very efficient stripping of the ionic liquid. For these experiments, the differential mass balance described in equation 6 , with $C_{f}^{*}=0$, can be used to determine the extraction overall mass transfer. The values obtained for the overall mass transfer coefficient were $3.59 \pm 0.11 \times 10^{-8} \mathrm{~m} . \mathrm{s}^{-1}$ and $5.24 \pm 0.21 \times 10^{-8} \mathrm{~m} . \mathrm{s}^{-1}$, respectively. Although slightly different, these values of the same magnitude as the overall mass transfer coefficient determined for the single extraction process $\left(7.88 \pm 0.35 \times 10^{-8} \mathrm{~m} \cdot \mathrm{s}^{-1}\right)$, as can be seen in Table 2 .

Table 2 Extraction and regeneration mass transfer coefficients for the systems ionic liquid +1 -hexanethiol $+n$-dodecane, using single extraction and integrated extraction/sweep gas regeneration, at $298.2 \mathrm{~K}$ and atmospheric pressure.

\begin{tabular}{ccc}
\cline { 2 - 3 } & $K_{E} \times 10^{-8}\left(\mathrm{~m} \cdot \mathrm{s}^{-1}\right)$ & $K_{R} \times 10^{-8}\left(\mathrm{~m} \cdot \mathrm{s}^{-1}\right)$ \\
\hline Single extraction & $7.88 \pm 0.35$ & \\
\hline $\begin{array}{c}\text { Integrated extraction + sweep gas } \\
\text { regeneration }\end{array}$ & & \\
$v_{g}=1.23 \mathrm{~cm} \cdot \mathrm{s}^{-1}$ & $4.90 \pm 1.49$ & \\
$v_{g}=7.84 \mathrm{~cm} \cdot \mathrm{s}^{-1}$ & $3.59 \pm 0.11$ & \\
$v_{g}=19.30 \mathrm{~cm} \cdot \mathrm{s}^{-1}$ & $5.24 \pm 0.21$ & \\
\hline
\end{tabular}

\section{Simulation of thiol transport}

As aforementioned, considering a complete regeneration of the ionic liquid, the mass transfer performance in the integrated process is controlled by the 1-hexanethiol transport in the ionic liquid phase, in the extraction module. Therefore, the overall mass transfer coefficient is directly affected by the operating conditions of the ionic liquid 
stream in the extraction membrane contactor. Aiming at understanding the effect of the ionic liquid fluid dynamics on the extraction process, the impact of increasing the ionic liquid linear velocities in the extraction contactor was evaluated by simulation, using the mass transfer model previously discussed. Additionally, the impact of operating at higher extraction temperature was also evaluated.

The ionic liquid velocities tested, $5 \mathrm{~cm} \cdot \mathrm{s}^{-1}$ and $10 \mathrm{~cm} \cdot \mathrm{s}^{-1}$, at a temperature of $298.2 \mathrm{~K}$, were chosen having in mind the limiting pressure drop allowed inside the module, considering the critical breakthrough pressure (3.85 bar at $298.2 \mathrm{~K}$ ). For each velocity, the pressure drop between the inlet and the outlet of the module was estimated, by using the Hagen-Poiseuille equation [17]:

$$
\Delta P=\frac{32 \mu_{I L} v_{I L} L_{f}}{d_{f i}^{2}} \times 10^{-5} \text { bar }
$$

where the $\mu_{I L}$ is the ionic liquid viscosity (Pa.s) at the operating temperature, the $L_{f}$ is the fibre length $(\mathrm{m})$ and the $d_{I L}$ is the fibre internal diameter $(\mathrm{m})$.

The pressure drop estimated for each tested velocity was of 1.8 bar and 3.6 bar, respectively, which do not exceed the critical breakthrough pressure.

Using the mass transfer relation described by equation 13 [47], the ionic liquid mass transfer coefficients increased significantly from $4.90 \times 10^{-8} \mathrm{~m} . \mathrm{s}^{-1}$ at $1 \mathrm{~cm} . \mathrm{s}^{-1}$, to $2.46 \times$ $10^{-7} \mathrm{~m} . \mathrm{s}^{-1}$ at $5 \mathrm{~cm} \cdot \mathrm{s}^{-1}$, and $4.96 \times 10^{-7} \mathrm{~m} \cdot \mathrm{s}^{-1}$ at $10 \mathrm{~cm} \cdot \mathrm{s}^{-1}$. This effect is shown in Figure 5 a). The increase of the ionic liquid velocity allows for enhancing the extraction performance due to its direct impact on the mass transfer coefficient increase, with a decreasing resistance to the thiol transport in the ionic liquid boundary layer.

$$
\frac{K_{\text {simulated }}}{K_{E}}=\left(\frac{v_{I L, \text { simulated }}}{v_{I L, E}}\right)^{1.01}
$$

A temperature increase leads to an improvement of the mass transfer (Figure 5 b)) by reducing the viscosity and density of the ionic liquid (reducing the ionic liquid boundary layer thickness) and increasing of the diffusion coefficient. The effect of temperature was simulated taking into consideration its various impacts in these properties, and also respecting the temperature restrictions of the hollow fibre membrane contactor of Liqui-Cel $^{\circledR}$, indicated by the manufacturer. Simulations for temperatures of $313.2 \mathrm{~K}$ and $333.2 \mathrm{~K}$ led to a the viscosity reduction of $\left[\mathrm{C}_{2} \mathrm{mim}\right]\left[\mathrm{CF}_{3} \mathrm{SO}_{3}\right]$ from $41 \mathrm{mPa}$.s at $298.2 \mathrm{~K}$ to $26.8 \mathrm{mPa} . \mathrm{s}$ [48] and $14.7 \mathrm{mPa}$.s [48], and the density from $1379.1 \mathrm{~kg} \cdot \mathrm{m}^{-3}$ to 1371.5 $\mathrm{kg} \cdot \mathrm{m}^{-3}$ and $1354.9 \mathrm{~kg} \cdot \mathrm{m}^{-3}$, respectively. The diffusion coefficient, estimated by the 
Wilke-Chang correlation [49], increases from $4.12 \times 10^{-11} \mathrm{~m}^{2} \cdot \mathrm{s}^{-1}$ to $6.79 \times 10^{-11} \mathrm{~m}^{2} \cdot \mathrm{s}^{-1}$ and $1.28 \times 10^{-10} \mathrm{~m}^{2} \cdot \mathrm{s}^{-1}$, respectively.

Estimating the mass transfer coefficient using the relation in equation 14 [47], the benefit of increasing temperature can be observed in Figure $5 \mathrm{c}$ ). The correspondent overall mass transfer coefficients are $5.51 \times 10^{-8} \mathrm{~m} \cdot \mathrm{s}^{-1}$ and $6.54 \times 10^{-8} \mathrm{~m} . \mathrm{s}^{-1}$.

$$
\frac{K_{\text {simulated }}}{K_{E, 298.2 K}}=\frac{\left[\left(\frac{\rho}{\mu}\right)^{1.01}\left(\frac{\mu}{\rho \mathfrak{D}}\right)^{0.33}\right]_{T_{\text {simulated }}}}{\left[\left(\frac{\rho}{\mu}\right)^{1.01}\left(\frac{\mu}{\rho \mathfrak{D}}\right)^{0.33}\right]_{298.2 \mathrm{~K}}}
$$

As observed, the extraction process can be remarkably improved if optimal operating conditions are employed. When combining the ionic liquid fluid dynamics and the operating temperature, the thiol extraction performance is significantly improved. By the temperature increase, the pressure drop associated with the ionic liquid flow inside the fibre is also reduced. Therefore, higher ionic liquid velocities can be applied up to the critical breakthrough pressure at the operating temperature. Due to the nonexistence of data for the estimation of the critical breakthrough pressure at the operating temperature of $333.2 \mathrm{~K}$, the ionic liquid velocity for the simulation, at $333.2 \mathrm{~K}$, was selected to cause a pressure drop lower than 2 bar. A pressure drop of 1.96 bar is estimated for an ionic liquid velocity of $15 \mathrm{~cm} . \mathrm{s}^{-1}$. Figure $5 \mathrm{c}$ ) shows the overall improvement by increasing ionic liquid velocity and temperature. The estimated extraction mass transfer coefficient for these conditions is $1.0 \times 10^{-6} \mathrm{~m} . \mathrm{s}^{-1}$, reducing drastically the thiol extraction time from $50 \mathrm{~h}$ to only $3.5 \mathrm{~h}$. These results were not validated due to experimental restrictions.

Still, the results presented attest the remarkable potential for an effective thiol removal from a jet-fuel feed phase using an ionic liquid as a solvent in an integrated extraction/stripping process carried out in hollow fibre membrane contactors. 

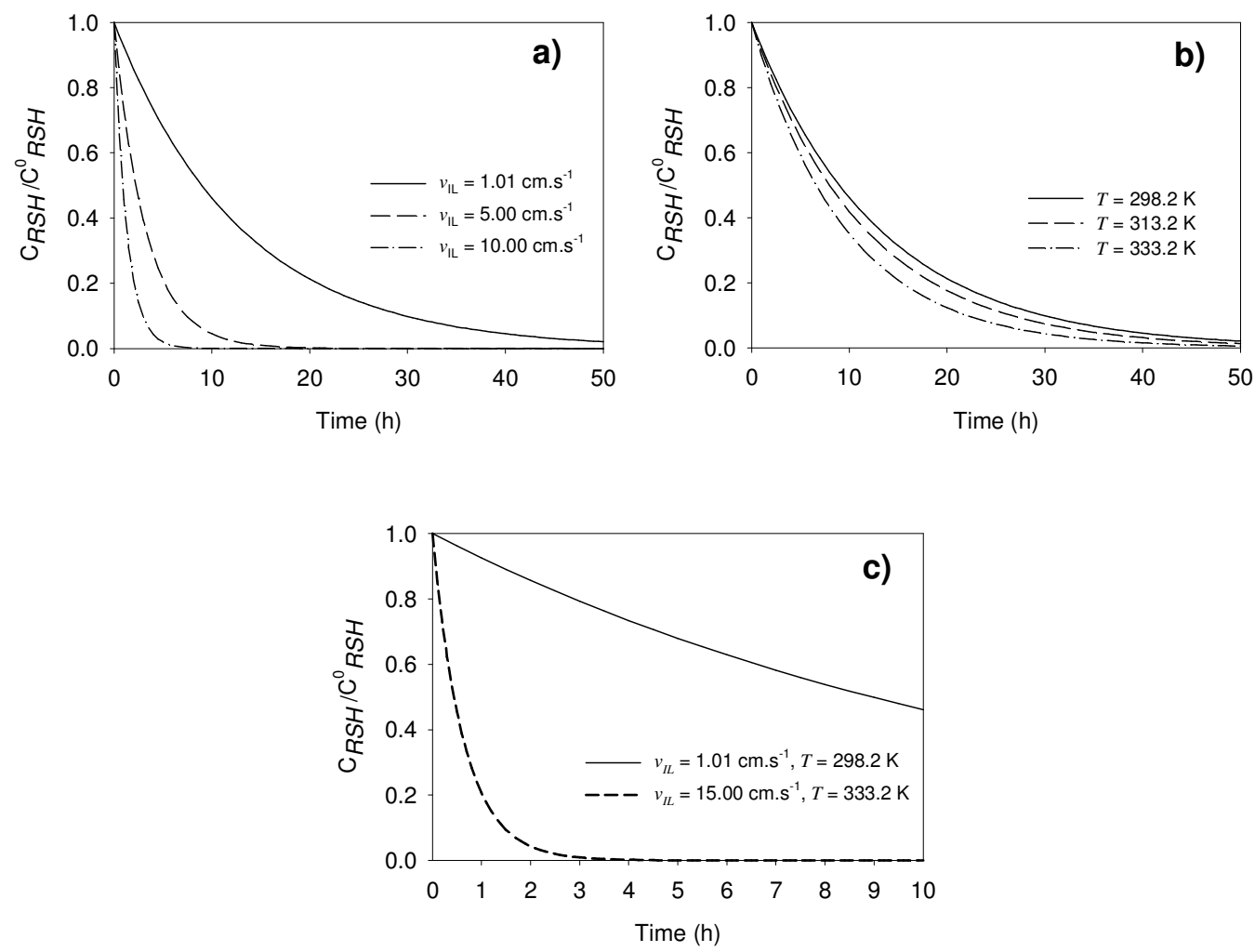

Figure 5 Simulated 1-hexanethiol concentration profile varying a) the ionic liquid velocity and b) the operating temperature. In c) the simulation is obtained combining both parameters studied in a) and b).

\section{Conclusions}

A new methodology for the desulphurization of "jet-fuel" streams, using a mixture of 1hexanethiol and $n$-dodecane as a model system, was proposed in this work. It consisted in a liquid extraction of the thiol using as an ionic liquid as the extracting solvent (1-ethyl-3-methylimidazolium triflate $\left[\mathrm{C}_{2} \mathrm{mim}\right]\left[\mathrm{CF}_{3} \mathrm{SO}_{3}\right]$ ), followed by its integrated regeneration. The separation process was carried out in hollow fibre membrane contactor in counter-current mode, which allowed for reducing the extraction time due to its high interfacial area $\left(3335 \mathrm{~m}^{2} / \mathrm{m}^{3}\right)$.

Simultaneously to the extraction, controlled by the thiol transport in the ionic liquid phase, the ionic liquid was regenerated in an integrated system. Two regeneration methods were tested: vacuum stripping and a sweep gas stream in the downstream side of the membrane. In the vacuum stripping process, the ionic liquid partially filled the fibre pores which add a second significant resistance to the thiol transport. This method was considered unfeasible for the re-extraction of thiols. Using a sweep gas stripping, a complete regeneration of the ionic liquid was possible, allowing for an 
improvement of the extraction performance as a result of the maximization of the concentration gradient, reducing the constrains related with the low distribution ratio of the system under study. A complete extraction of the thiol from the "jet-fuel" model stream was achieved, producing an ultra-low sulphur jet-fuel with sulphur content lower than 2 ppm, as envisaging by legislation for the use of ultra-low sulphur jet-fuel $(<10$ ppm S).

In an efficient integrated regeneration of the ionic liquid, the controlling step becomes the extraction of thiol from the feed phase to the ionic liquid phase. Simulations showed that the increase of the ionic liquid velocity and operating temperature can lead to a high decrease of the extraction time, i.e. from $50 \mathrm{~h}$ to $3.5 \mathrm{~h}$.

The approach reported in this paper offers significant benefits over the actual process for the removal of thiols. It is true that other solvent systems should be tested aiming to achieve higher distribution coefficients of the target solutes to the extracting phase, namely through the use of reactive extraction. It is important to emphasize the fact that this technology, involving an integrated membrane contactor extraction and stripping, was proved to be technically feasible. Pilot studies will follow in order to provide information about long-term operation and a precise evaluation of the process economics which, with a simple "back-of-the-envelope" calculation, seems extremely attractive.

\section{Acknowledgments}

This work was financed by national funding from Fundação para a Ciência e a Tecnologia (FCT) through projects Pest-C/EQB/LA0006/2011, PTDC/QUIQUI/121520/2010 and Pest-C/CTM/LA0011/2013. Ana R. Ferreira acknowledges the financial support from FCT and Galp Energia through the $\mathrm{PhD}$ scholarship SFRH/BDE/33835/2009. Luísa Neves acknowledges the financial support from FCT through the scholarship SFRH/BPD/64975/2009.

\section{References}

[1] B. Pawelec, R.M. Navarro, J.M. Campos-Martin, J.L.G. Fierro, Towards near zerosulfur liquid fuels: a perspective review, Catal Sci Technol, 1 (2011) 23-42.

[2] M. Francisco, A. Arce, A. Soto, Ionic liquids on desulfurization of fuel oils, Fluid Phase Equilibria, 294 (2010) 39-48.

[3] P.S. Kulkarni, C.A.M. Afonso, Deep desulfurization of diesel fuel using ionic liquids: current status and future challenges, Green Chemistry, 12 (2010) 1139-1149. 
[4] C. Song, An overview of new approaches to deep desulfurization for ultra-clean gasoline, diesel fuel and jet fuel, Catalysis Today, 86 (2003) 211-263.

[5] V.C. Srivastava, An evaluation of desulfurization technologies for sulfur removal from liquid fuels, Rsc Adv, 2 (2012) 759-783.

[6] K.S. Triantafyllidis, E.A. Deliyanni, Desulfurization of diesel fuels: Adsorption of 4,6DMDBT on different origin and surface chemistry nanoporous activated carbons, Chemical Engineering Journal, 236 (2014) 406-414.

[7] F. Subhan, B.S. Liu, Acidic sites and deep desulfurization performance of nickel supported mesoporous AIMCM-41 sorbents, Chemical Engineering Journal, 178 (2011) 69-77.

[8] Z.E.A. Abdalla, B. Li, Preparation of MCM-41 supported (Bu4N)4H3(PW11O39) catalyst and its performance in oxidative desulfurization, Chemical Engineering Journal, 200-202 (2012) 113-121.

[9] S. Werner, M. Haumann, P. Wasserscheid, Ionic Liquids in Chemical Engineering, Annu Rev Chem Biomol, 1 (2010) 203-230.

[10] A.R. Ferreira, L.A. Neves, J.C. Ribeiro, F.M. Lopes, J.A.P. Coutinho, I.M. Coelhoso, J.G. Crespo, Removal of thiols from model jet-fuel streams assisted by ionic liquid membrane extraction, Chemical Engineering Journal, 256 (2014) 144-154.

[11] N.S. Williams, M.B. Ray, H.G. Gomaa, Removal of ibuprofen and 4isobutylacetophenone by non-dispersive solvent extraction using a hollow fibre membrane contactor, Sep Purif Technol, 88 (2012) 61-69.

[12] R.M.C. Viegas, C.A.M. Afonso, J.G. Crespo, I.M. Coelhoso, Racemic resolution of propranolol in membrane contactors: Modelling and process optimisation, J Membrane Sci, 305 (2007) 203-214.

[13] R.M.C. Viegas, C.A.M. Afonso, J.G. Crespo, I.M. Coelhoso, Modelling of the enantio-selective extraction of propranolol in a biphasic system, Sep Purif Technol, 53 (2007) 224-234.

[14] R.M.C. Viegas, J.G. Crespo, I.M. Coelhoso, Hybrid modelling of the racemic resolution of propranolol in membrane contactors, Desalination, 200 (2006) 595-597.

[15] João G. Crespo, Isabel M. Coelhoso, R.C. Viegas, Membrane Contactors, in: Encyclopedia of Separation Processes, Academic Press, London, 2000, pp. 3303.

[16] A.K. Pabby, A.M. Sastre, State-of-the-art review on hollow fibre contactor technology and membrane-based extraction processes, J Membrane Sci, 430 (2013) 263-303.

[17] W.S.W. Ho, K.K. Sirkar, Membrane Handbook, Kluwer Academic Publishers, Boston 1992. 
[18] I.M. Coelhoso, M.M. Cardoso, R.M.C. Viegas, J.P.S.G. Crespo, Transport mechanisms and modelling in liquid membrane contactors, Sep Purif Technol, 19 (2000) 183-197.

[19] Y.W. Gong, H.X. Liu, X.N. Cheng, Experiments of mercaptans removal from FCC gasoline by $\mathrm{NaOH}$ aqueous in membrane contactor, Petroleum Science and Technology, 28 (2010) 903-910.

[20] X. Yang, Y.-M. Cao, R. Wang, Q. Yuan, Study on highly hydrophilic cellulose hollow fiber membrane contactors for thiol sulfur removal, J Membrane Sci, 305 (2007) 247-256.

[21] E. Bringas, M.F. San Román, A.M. Urtiaga, I. Ortiz, Integrated use of liquid membranes and membrane contactors: Enhancing the efficiency of $L-L$ reactive separations, Chemical Engineering and Processing: Process Intensification, 67 (2013) 120-129.

[22] A. Gugliuzza, A. Basile, 2 - Membrane contactors: fundamentals, membrane materials and key operations, in: A. Basile (Ed.) Handbook of Membrane Reactors, Woodhead Publishing, 2013, pp. 54-106.

[23] C.M. Gordon, M.J. Muldoon, Synthesis and purification, Ionic Liquids in Synthesis, (2008) 7-55.

[24] T. Welton, F. Endres, S.Z.E. Abedin, M. Antonietti, B. Smarsly, Y. Zhou, Inorganic Synthesis, in, 2008, pp. 569-617.

[25] M. Maase, lonic liquids in industrial processes: Re-invention of the wheel or true innovation?, lonic Liquids in Synthesis, (2008) 663-687.

[26] D. Dennewald, W.-R. Pitner, D. Weuster-Botz, Recycling of the ionic liquid phase in process integrated biphasic whole-cell biocatalysis, Process Biochemistry, 46 (2011) 1132-1137.

[27] W.G.W. Meindersma, F.S.A.F. Onink, A.R. Hansmeier, A.B. de Haan, Long Term Pilot Plant Experience on Aromatics Extraction with Ionic Liquids, Sep Sci Technol, 47 (2012) 337-345.

[28] Q. Gan, M.L. Xue, D. Rooney, A study of fluid properties and microfiltration characteristics of room temperature ionic liquids [C-10-min][NTf2] and N-8881[NTf2] and their polar solvent mixtures, Sep Purif Technol, 51 (2006) 185-192.

[29] M.T.G. Jongmans, J. Trampe, B. Schuur, A.B. de Haan, Solute recovery from ionic liquids: A conceptual design study for recovery of styrene monomer from 4-mebupy BF4, Chemical Engineering and Processing, 70 (2013) 148-161.

[30] J.-M. Andanson, F. Jutz, A. Baiker, Purification of ionic liquids by supercritical CO2 monitored by infrared spectroscopy, The Journal of Supercritical Fluids, 55 (2010) 395400 . 
[31] E. Kuhlmann, M. Haumann, A. Jess, A. Seeberger, P. Wasserscheid, lonic Liquids in Refinery Desulfurization: Comparison between Biphasic and Supported Ionic Liquid Phase Suspension Processes, Chemsuschem, 2 (2009) 969-977.

[32] A.F.M. Claudio, C.F.C. Marques, I. Boal-Palheiros, M.G. Freire, J.A.P. Coutinho, Development of back-extraction and recyclability routes for ionic-liquid-based aqueous two-phase systems, Green Chemistry, 16 (2014) 259-268.

[33] S. Wellens, R. Goovaerts, C. Moller, J. Luyten, B. Thijs, K. Binnemans, A continuous ionic liquid extraction process for the separation of cobalt from nickel, Green Chemistry, 15 (2013) 3160-3164.

[34] S. Wellens, T. Vander Hoogerstraete, C. Möller, B. Thijs, J. Luyten, K. Binnemans, Dissolution of metal oxides in an acid-saturated ionic liquid solution and investigation of the back-extraction behaviour to the aqueous phase, Hydrometallurgy, 144-145 (2014) 27-33.

[35] M.C. Kroon, J. van Spronsen, C.J. Peters, R.A. Sheldon, G.-J. Witkamp, Recovery of pure products from ionic liquids using supercritical carbon dioxide as a co-solvent in extractions or as an anti-solvent in precipitations, Green Chemistry, 8 (2006) 246-249.

[36] K. Haerens, S. Van Deuren, E. Matthijs, B. Van der Bruggen, Challenges for recycling ionic liquids by using pressure driven membrane processes, Green Chemistry, 12 (2010) 2182-2188.

[37] C. Abels, C. Redepenning, A. Moll, T. Melin, M. Wessling, Simple purification of ionic liquid solvents by nanofiltration in biorefining of lignocellulosic substrates, $\mathrm{J}$ Membrane Sci, 405-406 (2012) 1-10.

[38] V. García, H. Valkama, R. Sliz, A.W.T. King, R. Myllylä, I. Kilpeläinen, R.L. Keiski, Pervaporation recovery of $[\mathrm{AMIM}] \mathrm{Cl}$ during wood dissolution; effect of [AMIM]Cl properties on the membrane performance, J Membrane Sci, 444 (2013) 9-15.

[39] M.B. Shiflett, A.D. Shiflett, A. Yokozeki, Separation of tetrafluoroethylene and carbon dioxide using ionic liquids, Sep Purif Technol, 79 (2011) 357-364.

[40] J.G. Lu, C.T. Lu, Y. Chen, L. Gao, X. Zhao, H. Zhang, Z.W. Xu, CO2 capture by membrane absorption coupling process: Application of ionic liquids, Appl Energ, 115 (2014) 573-581.

[41] H.X. Guo, Z.M. Zhou, G.H. Jing, Kinetics of carbon dioxide absorption into aqueous [Hmim][Gly] solution, Int J Greenh Gas Con, 16 (2013) 197-205.

[42] H.R. Mortaheb, M. Mafi, B. Mokhtarani, A. Sharifi, M. Mirzaei, N. Khodapanah, F. Ghaemmaghami, Experimental kinetic analysis of ethylene absorption in ionic liquid [Bmim]NO3 with dissolved $\mathrm{AgNO} 3$ by a semi-continuous process, Chemical Engineering Journal, 158 (2010) 384-392. 
[43] S. Ren, Y. Hou, W. Wu, W. Liu, Purification of Ionic Liquids: Sweeping Solvents by Nitrogen, Journal of Chemical \& Engineering Data, 55 (2010) 5074-5077.

[44] A.R. Ferreira, M.G. Freire, J.C. Ribeiro, F.M. Lopes, J.G. Crespo, J.A.P. Coutinho, Ionic liquids for thiols desulfurization: Experimental liquid-liquid equilibrium and COSMO-RS description, Fuel, 128 (2014) 314-329.

[45] ASTM D3227 - Standard Test Method for (Thiol Mercaptan) Sulfur in Gasoline, Kerosine, Aviation Turbine, and Distillate Fuels (Potentiometric Method), in, ASTM International, 2013.

[46] D.W. Green, R.H. Perry, Perry's Chemical Engineers' Handbook, The McGraw-Hill Companies, Inc., United States of America, 1934.

[47] R.M.C. Viegas, M. Rodríguez, S. Luque, J.R. Alvarez, I.M. Coelhoso, J.P.S.G. Crespo, Mass transfer correlations in membrane extraction: Analysis of Wilson-plot methodology, J Membrane Sci, 145 (1998) 129-142.

[48] H. Rodríguez, J.F. Brennecke, Temperature and Composition Dependence of the Density and Viscosity of Binary Mixtures of Water + Ionic Liquid, Journal of Chemical \& Engineering Data, 51 (2006) 2145-2155.

[49] R.C. Reid, J.M. Prausnitz, B.E. Poling, The properties of gases and liquids, 4th ed., McGraw-Hill, New York, 1987. 